\title{
Correction to: Possibilities for Linguistic Summaries in Cognitive Cities
}

\author{
Miroslav Hudec
}

\section{Correction to:}

Chapter "Possibilities for Linguistic Summaries in Cognitive Cities" in: E. Portmann et al. (eds.), Designing Cognitive Cities, Studies in Systems, Decision and Control 176, https://doi.org/10.1007/978-3-030-00317-3_3

The affiliation "Faculty of Economic Informatics, University of Economics in Bratislava" of author "Prof. Miroslav Hudec" in the original version of the book has been changed to "Faculty of Organizational Sciences, University of Belgrade" in the chapter "Possibilities for Linguistic Summaries in Cognitive Cities". The correction book has been updated with the change. 